\title{
Altered mitochondrial function in insulin-deficient and insulin-resistant states
}

\author{
Gregory N. Ruegsegger, Ana L. Creo, Tiffany M. Cortes, Surendra Dasari, and K. Sreekumaran Nair \\ Division of Endocrinology, Diabetes, Metabolism, and Nutrition, Mayo Clinic, Rochester, Minnesota, USA.
}

\begin{abstract}
Diabetes profoundly alters fuel metabolism; both insulin deficiency and insulin resistance are characterized by inefficient mitochondrial coupling and excessive production of reactive oxygen species (ROS) despite their association with normal to high oxygen consumption. Altered mitochondrial function in diabetes can be traced to insulin's pivotal role in maintaining mitochondrial proteome abundance and quality by enhancing mitochondrial biogenesis and preventing proteome damage and degradation, respectively. Although insulin enhances gene transcription, it also induces decreases in amino acids. Thus, if amino acid depletion is not corrected, increased transcription will not result in enhanced translation of transcripts to proteins. Mitochondrial biology varies among tissues, and although most studies in humans are performed in skeletal muscle, abnormalities have been reported in multiple organs in preclinical models of diabetes. Nutrient excess, especially fat excess, alters mitochondrial physiology by driving excess ROS emission that impairs insulin action. Excessive ROS irreversibly damages DNA and proteome with adverse effects on cellular functions. In insulin-resistant people, aerobic exercise stimulates both mitochondrial biogenesis and efficiency concurrent with enhancement of insulin action. This Review discusses the association between both insulin-deficient and insulin-resistant diabetes and alterations in mitochondrial proteome homeostasis and function that adversely affect cellular functions, likely contributing to many diabetic complications.
\end{abstract}

\section{Introduction}

The worldwide prevalence of diabetes, especially type 2 diabetes (T2D), and the associated global economic burden are substantial and rapidly growing, with major adverse impacts on health and social security systems (1). Although T2D, characterized by insulin resistance and insufficient insulin secretion, and type 1 diabetes mellitus (T1D), characterized by absolute insulin deficiency, have different etiologies (2), both profoundly derange fuel metabolism, including metabolism of glucose, fat, and amino acids (AAs), the main energy sources for humans. Moreover, well-documented upregulation of whole-body oxygen consumption in T1D and T2D indicates higher resting energy expenditure in untreated individuals (3-6). Emerging evidence clearly indicates that these alterations in energy metabolism can be traced to mitochondria, organelles that produce the majority of a cell's ATP from macronutrients through cellular respiration and oxidative phosphorylation (OXPHOS).

Mitochondria's chief role, cellular respiration, is in turn associated with various functions, including reactive oxygen species (ROS) production and detoxification; $\beta$-oxidation and processing of acetyl-CoA, generated from fatty acids (FAs), glucose, and AA oxidation through the tricarboxylic acid (TCA) cycle; and mitochondrial electron transport chain (ETC) complex activities (7, 8). Mitochondria possess approximately 1,500 predominantly nuclear-encoded proteins in addition to 13 proteins encoded by their own DNA (mtDNA). In humans, mtDNA contains 37 genes, which also encode 22 transfer RNAs and two RNA subunits, and

Conflict of interest: The authors have declared that no conflict of interest exists Reference information: J Clin Invest. 2018;128(9):3671-3681.

https://doi.org/10.1172/JCI120843. all are critical to maintaining mitochondrial function (9). mtDNA replication, mitochondrial biogenesis (involving transcription, translation, and proteome homeostasis), and mitochondrial function are tightly regulated and highly complex. As almost all cellular processes require ATP, it is unsurprising that both physiological and pathological alterations in energy demand and fuel supply influence mitochondrial functions, including mitochondrial dynamics (fusion and fission), biogenesis, and mitophagy (10). Insulin, the predominant hormone involved in fuel metabolism, is involved in many cellular functions, including protein turnover, a highly ATP-dependent process; moreover, insulin impairment in diabetes is associated with altered energy metabolism.

Here, we synthesize results showing insulin's key role in mitochondrial function and in regulation of mitochondrial proteome homeostasis, including biogenesis, at the transcriptional, translational, and posttranslational levels, as well as in mitophagy. Our primary aim is to broadly highlight how insulin deficiency in T1D and insulin resistance in T2D (and other conditions such as polycystic ovarian syndrome) have detrimental effects on mitochondrial function, primarily in skeletal muscle. We also provide data on mitochondrial function in heart, liver, kidney, adipose tissue (AT), and brain. Detailed review of mitochondrial functions in other aspects of metabolism and in specific tissues is beyond the scope of this Review, but readers are referred to other publications (11-15). Additionally, we discuss how altered mitochondrial function can adversely affect insulin's actions. We propose that impaired insulin secretion and action may explain many of the alterations in mitochondrial function observed in T1D and T2D, respectively, and in turn explain how altered mitochondrial function contributes to many pathologies in diabetes. 


\section{Insulin regulates mitochondrial biogenesis, degradation, and function}

In canonical insulin signaling, insulin binds to insulin receptor (IR), inducing IR autophosphorylation, recruitment of insulin receptor substrate (IRS) adaptor proteins, and AKT pathway stimulation (16). The insulin/IRS/AKT pathway is central to glucose homeostasis and regulates multiple ATP-dependent processes, including stimulating glucose uptake in muscle and AT, inhibiting glycogenosis and glucose release in the liver, promoting lipid synthesis and storage in liver and AT, and regulating protein synthesis and degradation. The insulin/IRS/AKT pathway's regulation of mTOR activity and FOXO transcription factors has key implications for mitochondrial function, as mTOR $(17,18)$ and FOXO1 $(19,20)$ control mitochondrial oxidative function via regulation of PPAR $\gamma$ coactivator $1 \alpha$ (PGC1A). PGC1A is a master regulator of mitochondrial biogenesis via the transcription factors nuclear respiratory factor 1 (NRF1) and NRF2, which control nuclearencoded and mitochondrial-encoded genes via transcription factor A, mitochondrial (TFAM) (ref. 21 and Figure 1). All nuclearencoded mitochondrial proteins are synthesized in cytosolic ribosomes and imported into mitochondria, whereas mitochondrial ribosomes synthesize 13 mitochondrial proteins (22). Mitochondrial complexes are formed with both nuclear-encoded imported proteins and mitochondrial-encoded proteins. Insulin's role in these mitochondrial outer and inner membrane transporters and complex formation remains unclear.

Mitochondrial protein synthesis and turnover are critical for maintaining protein quality and function (23-25). Insulin's effects on protein synthesis vary considerably between different proteins and tissues (26). Stump et al. (27) demonstrated that high physiological-level insulin infusion in healthy humans increased maximal ATP production in freshly isolated mitochondria from human skeletal muscle. Similarly, insulin infusion increased mRNA levels of mitochondrial genes (e.g., NADH dehydrogenase subunit IV [MT-ND4]) and nuclear genes encoding mitochondrial proteins (e.g., cytochrome $c$ oxidase subunit IV [COX4])) increased mitochondrial protein synthesis, and increased activities of the key metabolic enzymes COX and citrate synthase (CS) in muscle. In healthy humans, high insulin concentrations stimulate mitochondrial protein synthesis in muscle, but only when coinfused with AAs (28), as acute insulin infusion lowers plasma AA concentrations by suppressing protein degradation $(29,30)$.

Like mitochondrial protein synthesis, increases in mitochondrial enzyme activities and ATP production also depend on AA availability. In healthy adults, insulin infusion without AA supplementation upregulated the mRNA expression of COX3, PGC1A, and NRF1; however, insulin alone failed to increase muscle mitochondrial protein synthesis, COX and CS activity, ATP production, and phosphorylation of the protein synthesis activators mTOR, $4 \mathrm{EBP} 1$, and $\mathrm{p}^{\mathrm{s}} \mathrm{O}^{\mathrm{s} \mathrm{K}}$ (31). Similarly, Ling et al. (32) associated increased muscle PGC1A mRNA with increased glucose oxidation following insulin infusion but noted that PGC1A protein level was unaltered. These observations $(27,28,31,33)$ indicate that insulin stimulates transcription of specific genes with potential effects on mitochondrial function, but only enhances mitochondrial protein expression and function when appropriate AA concentra- tions are present. Insulin inhibits not only degradation of endogenous proteins but also fat storage. Thus, when carbohydrate alone is ingested, insulin signaling promotes carbohydrate utilization for energy needs, preserving protein and fat stores. Since both AAs and insulin are needed for protein synthesis, carbohydrate or fat alone is unlikely to promote protein synthesis. Not surprisingly, protein ingestion is associated with higher thermogenesis than carbohydrate and fat ingestion, likely because of protein synthesis's higher ATP demand (34). It remains undetermined whether carbohydrate-induced increases in insulin signaling fail to stimulate protein synthesis in muscle (especially mitochondria) in order to reserve AAs for synthesis of essential proteins, such as clotting factors in liver, when AA availability is limited.

Gene manipulation studies in mice have provided molecular links between insulin signaling and mitochondrial function. IR deletion in muscle, heart, and brain decreases mitochondrial respiration and increases oxidative stress (35-37). It also impairs ATP production and FA oxidation (FAO) in the heart (35). Adipose-specific IR knockout decreases mitochondrial content and oxygen consumption in brown AT (BAT), while depleting white AT (WAT) mass by over $90 \%$ (38). Similarly, ATP production is decreased in $\beta$ cell-specific IR-knockout mice despite increased oxygen consumption, and restoring IR expression in $\beta$ cells restored deficits in mitochondrial ATP production, suggesting that insulin regulates $\beta$ cell mitochondrial function (39). The cardiomyocyte-specific deletion of Irs1 and Irs 2 decreased ADP-stimulated mitochondrial oxygen consumption and ATP production concomitant with downregulation of OXPHOS and FAO genes (40). Similar impairments in mitochondrial FAO and mitochondrial morphology in the heart were observed following double knockout (DKO) of IR and IGF1 receptor (IgfIr), whose signaling cascades converge at IRS proteins (41).

Studies in Irs1/2-DKO mice provided mechanistic links between hepatic insulin action and mitochondrial function. Blocking hepatic insulin signaling in Irs1/2-DKO mice led to insulin resistance and FOXO1 hyperactivation, which disrupted ETC complexes and reduced $\mathrm{NAD}^{+}$concentration (42). Consequently, the $\mathrm{NAD}^{+}$-dependent protein deacetylase SIRT1 reduces its deacetylation of PGC1A, decreasing mitochondrial biogenesis and drastically impairing mitochondrial coupling and ATP production (19). Thus, insulin may enhance mitochondrial function through redox regulation of PGC1A.

Recent studies show that insulin stimulates mitochondrial respiration in isolated cortical neurons from healthy mice but not Alzheimer's disease-prone (AD-prone) apolipoprotein E $\varepsilon 4$-knockin mice (43). Given that $80 \%$ of $\mathrm{AD}$ patients display impaired glucose tolerance or T2D (44), and the AD brain displays insulin resistance and impaired mitochondrial function $(45,46)$, strategies that enhance insulin sensitivity in diabetes may also have therapeutic value in $\mathrm{AD}$. Collectively, these data demonstrate insulin's importance for normal mitochondrial function in multiple tissues.

\section{Effects of insulin deficiency on mitochondrial function}

T1D results from insulin deficiency and produces long-term macrovascular and microvascular complications. Alterations in cellular oxidation and ATP production likely contribute to the pathogene- 
A

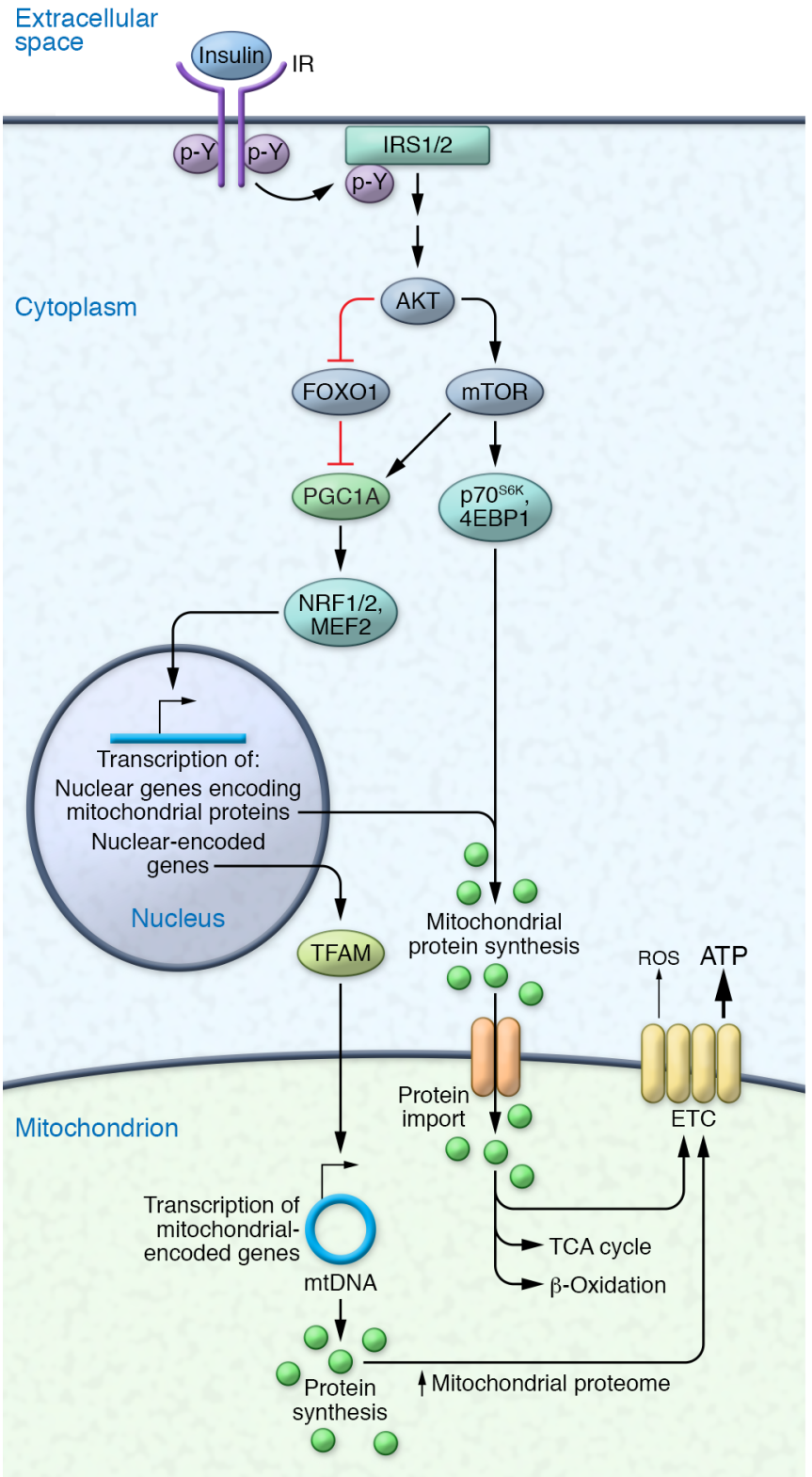

B

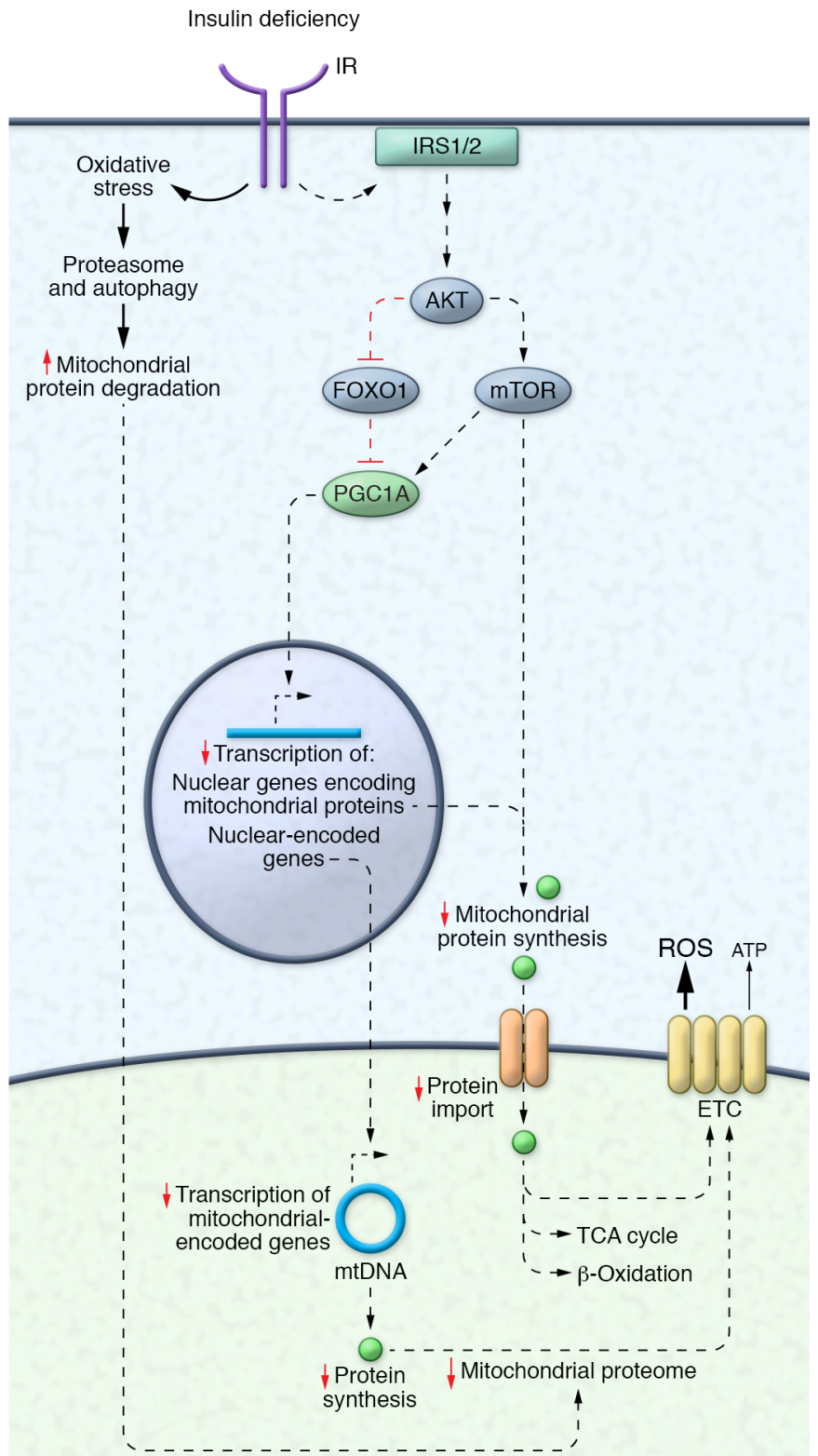

Figure 1. The mitochondrial proteome in the presence and absence of insulin signaling. (A) Insulin binding to the insulin receptor (IR) initiates a downstream signaling cascade leading to the phosphorylation of insulin receptor substrates (IRS1/2) and activation of AKT, the major node of insulin signaling. Of the many downstream effectors of AKT, the inhibition of FOXO1 influences the expression and activity of PPAR $\gamma$ coactivator $1 \alpha$ (PGC1A), which activates transcription factors (e.g., myocyte enhancer factor 2 [MEF2], nuclear respiratory factor 1 [NRF1], NRF2) that control nuclear-encoded mitochondrial gene expression. PGC1A also enhances the transcription of mitochondrial genes through transcription factor A, mitochondrial (TFAM). In the presence of appropriate amino acid concentrations, activation of mTOR and its downstream targets increases the synthesis of nuclear-encoded mitochondrial proteins in the cytoplasm, which are imported into the mitochondria to form TCA cycle, $\beta$-oxidation, and ETC complex proteins. Mitochondrial-encoded genes are synthesized in the mitochondria and form ETC complex proteins. Collectively, these increase the mitochondrial proteome and ATP production. (B) Insulin deficiency decreases the transcription of nuclear-encoded and mitochondrial-encoded mitochondrial genes and the synthesis of mitochondrial proteins, and increases oxidative stress and gene expression central to the proteasome pathway (e.g., the E3 ubiquitin ligase TRIM63) and autophagy pathway (e.g., Beclin), leading to increased degradation of mitochondrial proteins. Collectively, these responses decrease the mitochondrial proteome and ATP production. Additional abbreviations: 4EBP1, eukaryotic translation initiation factor 4E-binding protein 1; p70 $56 \mathrm{~K}, 70-\mathrm{kDa}$ ribosomal S6 kinase.

sis of diabetes-related complications. Benedict and Joslin's seminal findings before the discovery of insulin showed that wholebody oxygen consumption is increased in untreated T1D (47), but this observation was criticized because the comparison was with similarly wasted nondiabetic controls who had lower whole-body oxygen consumption (48). More recent observations show that transient withdrawal from insulin in insulin-treated T1D increased within-individual whole-body oxygen consumption and energy 
expenditure; these were also elevated in comparison with predicted energy values for non-T1D people of similar age and body composition $(4,49)$. Moreover, glucagon, whose effects on blood glucose counteract insulin's, has a thermogenic effect (50). Further studies have shown that high glucagon concentrations during insulin deficiency may explain increased oxygen consumption (49), suggesting that the liver, which is rich in glucagon receptors, mediates this observed increase in oxygen consumption. Glucagon promotes gluconeogenesis (4) and increased protein turnover (34, 51), both ATP-dependent processes. However, many other insulindependent cellular processes involving energy storage, including glycogen synthesis and lipogenesis, are reduced during insulin deficiency and thus reduce ATP demand (4), prompting a hypothesis that insulin deficiency causes uncoupling of mitochondrial respiration pathways and thereby increases energy waste.

In support of the uncoupled mitochondrial respiration hypothesis, it has been shown that despite increasing wholebody oxygen consumption, transient insulin deficiency in T1D patients decreased maximal ATP production in mitochondria isolated from muscle and downregulated expression of TCA and OXPHOS mRNA (52). These results were concurrent with increased inflammation, cytoskeleton signaling, and mRNA expression of integrin signaling proteins, suggesting potential interaction between these important pathways, mitochondrial function, and associated metabolic derangement; however, these observations may be secondary to hyperglycemia and increased metabolism of FAs, AAs, and ketones that occur following insulin deficiency (52). Insulin treatment maintains mitochondrial function in T1D patients, as resting or postexercise mitochondrial capacity and maximal oxidative ATP synthesis were unchanged in in vivo measurements from the calf muscle of treated T1D patients compared with nondiabetic controls (53). However, among the diabetic patients, elevated hemoglobin A1c, a blood-based marker of glycemic control, negatively correlated with mitochondrial capacity (53), suggesting that reduced insulin action and/or hyperglycemia adversely affects mitochondrial capacity.

Insulin deprivation impairs mitochondrial function in muscle. Recent proteomic and lipidomic studies have provided mechanistic insight into altered muscle mitochondrial function during insulin deficiency. Zabielski et al. compared mice with streptozotocin-induced diabetes (STZ mice) continuously treated with insulin implants and mice in which insulin implants were removed after the reestablishment of healthy glycemic control (54). Insulin deprivation did not significantly change ex vivo maximal mitochondrial oxygen consumption but led to significant declines in coupling efficiency and ATP production in isolated muscle mitochondria, concurrent with marked increases in ROS emission that caused oxidative damage to proteins. The above changes were explained on the basis of substantial downregulation of mitochondrial proteins involved in OXPHOS, TCA cycle, and $\beta$-oxidation in comparison with nondiabetic controls. However, insulin treatment prevented deficits in mitochondrial function, supporting the hypothesis that insulin is critical to maintaining mitochondrial proteome and functional homeostasis.

Insulin deprivation in STZ mice also substantially increased mitochondrial protein degradation and markers of mitophagy (Beclin) and proteasome degradation (E3 ubiquitin ligase
TRIM63), primary protein degradation pathways (55). Mitophagy, the specific autophagic targeting of mitochondria, is the primary pathway for degrading mitochondrial proteins (56). Thus, mitophagic signaling is likely upregulated during insulin deficiency to remove damaged mitochondria. Both STZ mice and T1D humans showed that insulin deficiency selectively increased the peptides in muscle that represent in vivo degradation of proteins involving mitochondrial function (e.g., ATP synthase subunit- $\gamma$ and COX6) and protein translation (55). These studies suggest that insulin deficiency in T1D increases muscle mitochondrial protein degradation, leading to reduced mitochondrial protein expression and impaired mitochondrial function.

Paradoxically, proteins involved in myocellular uptake of FAs, muscular glycogen breakdown, and glycolysis were upregulated by insulin deprivation, while mitochondrial proteins involved in $\beta$-oxidation were downregulated, leading to the accumulation of short-chain acyl-carnitines, ceramides, and incomplete FA $\beta$-oxidation products $(54,57)$. Similarly, treating mouse myotubes with the FA palmitate in the presence of a $\beta$-oxidation inhibitor reduced mitochondrial coupling and increased ROS emission, suggesting that incomplete $\beta$-oxidation and increased accumulation of intramuscular lipids and lipid metabolites impair mitochondrial function during insulin deprivation (54).

Mitochondrial dysfunction in diabetic cardiomyopathy. Altered mitochondrial function in T1D is central to the progression of diabetic cardiomyopathy (DCM), a leading cause of heart failure and death among diabetic patients. In the Akita T1D mouse model, which develops diabetes as a consequence of a single-base pair substitution in Ins2, maximal ADPstimulated mitochondrial respiration and ATP synthesis decreased despite unchanged ROS emission in cardiac tissue (58). Similarly, mRNA levels of transcriptional regulators of mitochondrial mass and function (e.g., Pgc1a, Pgc1b, Tfam) were downregulated in Akita mouse hearts (59). Proteomic analysis of OVE26 mice, a model of early-onset T1D in which transgenic overexpression of calmodulin in $\beta$ cells leads to deficient insulin production, revealed that mitochondrial proteins were upregulated in DCM, corresponding with increased mitochondria number and area, although mitochondria had severely damaged morphology and decreased respiration (60). Similarly, mitochondria in coronary epithelial cells of STZ mice and mitochondria from human coronary epithelial cells exposed to high glucose are fragmented, suggesting that altered mitochondrial dynamics influence endothelial function in T1D, an effect that is secondary to increased oxidative stress (60). Proteomic and microarray analyses in the hearts of rats with STZ-induced diabetes also suggest increased cardiac FAO, in addition to modest reductions in ETC proteins that may impair ATP synthesis $(60,61)$. These studies suggest that increased oxidative stress likely diminishes cardiac mitochondrial function in T1D, which may promote protein damage and coincident compensatory mitochondrial biogenesis, depending on the model organism.

Diabetes-induced mitochondrial impairments in the kidney. Diabetes is the leading cause of kidney failure and kidney transplantation, and roughly $25 \%$ diabetic adults have kidney disease (62). Various rodent models of T1D display impairments in kidney mitochondrial functions, such as increased basal membrane 
potential, oxidized glutathione level, and $\mathrm{H}_{2} \mathrm{O}_{2}$ production; alterations in mitochondrial respiration; and decreased ETC complex protein activities (63-66). Insulin treatment appeared ineffective at correcting alterations in kidney mitochondrial respiration in T1D (64). Studies from Akita T1D mice suggest that morphology and function of renal mitochondria are minimally affected (59). Studies on kidney mitochondrial function in T1D patients are limited, although the development of T1D renal disease is associated with specific methylation patterns of genes affecting mitochondrial function (67).

Influence of T1D on brain mitochondrial function. How T1D affects mitochondrial function in the CNS is unclear. Studies in rodents have concluded that the brain may be spared from alterations to mitochondrial morphology and function in T1D $(59,68$, 69). However, increased NRF2 protein levels and mtDNA copy number were observed in the cortex during insulin deficiency, suggesting that compensatory mechanisms protect the CNS from the effects of impaired mitochondrial function (69). It is important to study specific areas of the brain that are rich in IRs (e.g., hypothalamus, hippocampus, and cortex) to clearly evaluate whether insulin deficiency or resistance affects the brain's mitochondrial homeostasis. Additionally, human studies testing the effect of insulin withdrawal on in vivo brain mitochondrial functions are lacking and require measurement of mitochondrial function by noninvasive approaches such as NMR spectroscopy. As insulin (70) and mitochondrial function $(71,72)$ are implicated in multiple brain-related diseases (e.g., neurodegeneration, mood disorders), there is a critical need to investigate how insulin and T1D influence brain mitochondrial function.

In summary, insulin deficiency with and without concurrent hyperglycemia alters mitochondrial function in multiple organs. The impact of insulin deficiency and resulting hyperglycemia on mitochondrial function is tissue-specific, although it affects mostly tissues with high glucose uptake, including muscle, heart, kidney, and brain $(73,74)$.

\section{Insulin resistance and T2D mutually influence mitochondrial function}

Alterations in mitochondrial function that implicate insulin resistance mechanisms have stimulated substantial interest $(75$, 76). T2D is much more prevalent than T1D, and etiologically, insulin resistance is the primary factor leading to insufficient $\beta$ cell responses to increasing blood glucose levels. Moreover, insulin resistance in muscle occurs in a variety of conditions, including obesity, polycystic ovarian syndrome (PCOS), and hypertension. Various features of mitochondrial function are impaired in insulin-resistant muscle; however, the causal relationship between impaired mitochondrial oxidative capacity and insulin resistance is highly debated.

Mitochondrial function in insulin-resistant muscle. Kelley and colleagues $(75,77)$ reported decreased mitochondrial enzymatic activity, content, and FAO in muscle from adults with obesity and/ or T2D during insulin resistance. Additional studies confirmed that mitochondrial content is decreased and many factors regulating mitochondria are altered in obese, insulin-resistant adults as well as the offspring of parents with T2D $(33,78-82)$. These findings formed the basis for the notion that decreased mitochondrial oxidative capacity leads to accumulation of intramuscular lipids, which in turn promote the development of insulin resistance. This hypothesis is supported by in vivo reports that the incorporation of ${ }^{13} \mathrm{C}$-acetate into glutamate and mitochondrial phosphorylation was approximately $30 \%$ lower in muscle of insulin-resistant versus lean individuals $(81,83)$. However, muscle's resting energy demand is very low compared with its maximal oxygen uptake, which can increase approximately 150 -fold during maximal exercise in well-trained individuals (84), and it is argued that a $30 \%$ reduction in mitochondrial content or decrease in energetics would not influence $\mathrm{FAO}$ at rest (85).

Insulin resistance is not always associated with reduced mitochondrial respiration, as reported in rodents on a high-fat diet (HFD) (86-89) or in humans (90). Weight loss by caloric restriction in obese people enhanced insulin sensitivity but did not improve maximal mitochondrial oxidative capacity in isolated mitochondria or mitochondrial content (91, 92). Moreover, high-intensity interval training enhanced maximal mitochondrial function in isolated mitochondria in offspring of individuals with T2D, but failed to improve insulin sensitivity, in contrast to its effects in the offspring of nondiabetic mothers (93). Animals with severely impaired mitochondrial function and increased myocellular fat also demonstrated dissociation between insulinstimulated glucose uptake in muscle and mitochondrial deficiency $(94,95)$. However, HFD has been shown to increase muscle mitochondrial ROS emission that adversely affects insulin sensitivity (96) despite increasing mitochondrial respiration (88). Additionally, overexpressing the antioxidant enzyme catalase in muscle mitochondria completely preserved insulin sensitivity despite HFD (96), supporting the notion that insulin resistance results from oxidative stress. Similarly, maximal ex vivo mitochondrial respiration and content did not differ in young, lean people versus obese, insulin-resistant people despite increased $\mathrm{H}_{2} \mathrm{O}_{2}$ emission in the obese group, suggesting that reductions in mitochondrial respiratory capacity and content are not required for the initial manifestation of insulin resistance (97). Rather, excessive ROS emission may lead to the serine phosphorylation of IRS proteins, thus inhibiting insulin signaling (98). Collectively, these studies support a hypothesis that insulin sensitivity and mitochondrial function mutually influence each other, possibly promoting a cycle whereby insulin resistance further impairs mitochondrial function, and vice versa (Figure 2).

Women with PCOS are insulin-resistant, but their muscle has similar maximal mitochondrial oxygen flux to insulin-sensitive lean women's, despite displaying lower mitochondrial coupling and phosphorylation efficiencies and higher ROS emission (99). Moreover, 12 weeks of aerobic exercise training corrected mitochondrial abnormalities besides improving insulin sensitivity in women with PCOS (99). These results, together with the observation that high physiological insulin induced enhancement of mitochondrial oxidative capacity in nondiabetic but not in insulinresistant T2D people (27), suggest that interactions between insulin resistance and mitochondrial abnormalities are more complex than the previous notion that reduced muscle mitochondrial respiration may cause insulin resistance. The reduced mitochondrial response to insulin also is consistent with reduced thermic response to meals and hyperinsulinemic-euglycemic 


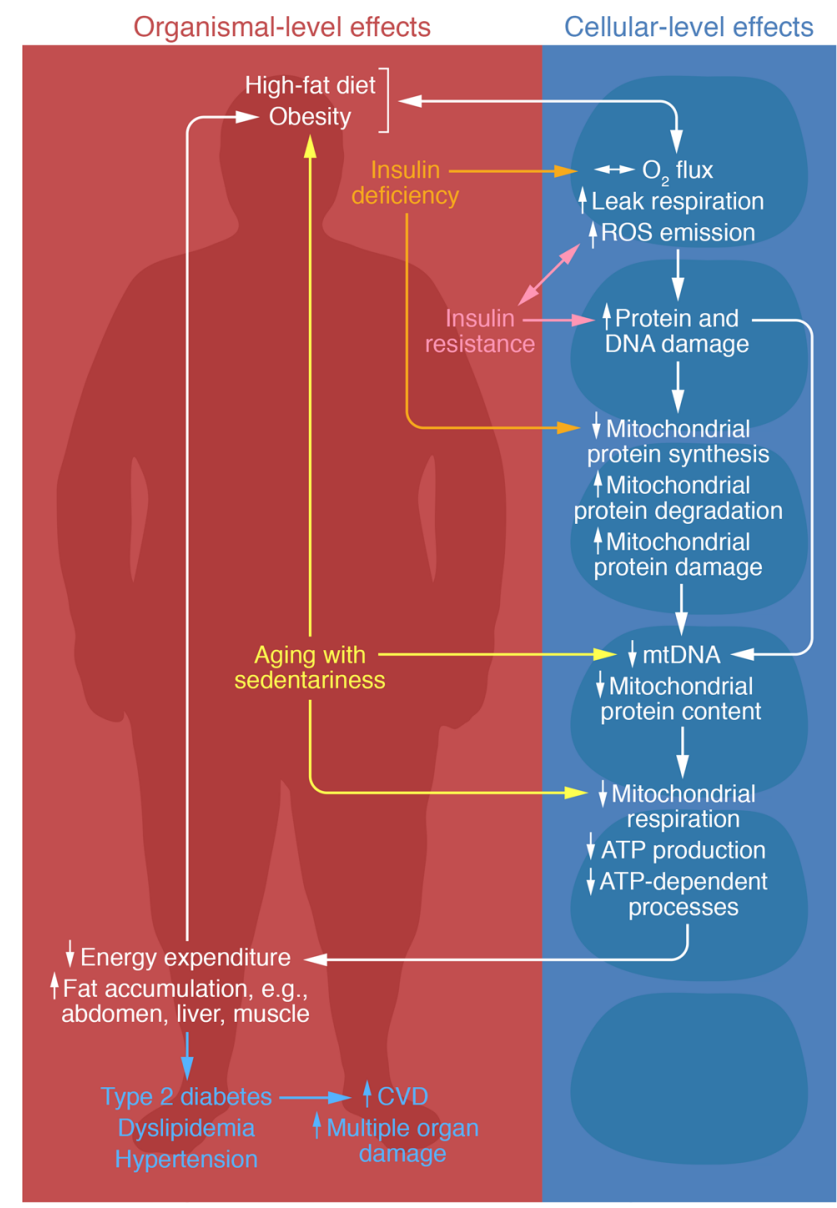

Figure 2. Proposed interactions between decreased insulin sensitivity, insulin deficiency, and impaired mitochondrial function in skeletal muscle and in the pathophysiology of diabetes and its complications. Excess nutrient overload and high-fat diet increase leak respiration and ROS emission, which contributes to insulin resistance and protein and DNA damage. Conversely, insulin resistance enhances leak respiration and ROS emission and damages protein and DNA. Similarly, insulin deficiency increases leak respiration and ROS emission, and decreases mitochondrial protein synthesis and increases degradation of mitochondrial proteins. Damage to protein and DNA also contributes to decreased mitochondrial protein synthesis and increased mitochondrial protein degradation and damage, as well as decreases mtDNA and protein content. Lower mitochondrial content and its quality also impair mitochondrial respiration, ATP production, and ATP-dependent processes. Impairments in mitochondrial ATP production and ATP-dependent processes (e.g., protein turnover) lead to declines in many cellular functions, including those in mitochondria. Reduced ATP availability and ROS-induced damage to proteins and DNA likely contribute to age-related sarcopenia and frailty that, in combination with sedentariness, contribute to increased fat accumulation, decreased energy expenditure, and type 2 diabetes and its complications. CVD, cardiovascular disease.

clamp reported in T2D $(5,6)$. It also is important to consider the implication of observations that $\mathrm{T} 2 \mathrm{D}$ individuals require lower rates of glucose infusion to maintain similar glucose levels than nondiabetic controls during high-dose insulin infusion. Most of the increased oxygen consumption following glucose/insulin administration is used for disposing glucose, and insulin itself has only a small effect (100), thus supporting a notion that the lack of increased ATP production in T2D individuals during high-dose insulin infusion may arise from lower amounts of glucose infusion needed to maintain euglycemia, linking insulin resistance directly to reduced mitochondrial response. It is clear, however, that both insulin deficiency and resistance adversely affect mitochondrial coupling efficiency and increase oxidative stress.

As in T1D, decreased expression of OXPHOS genes is a potential molecular basis for altered mitochondrial function in T2D. Initial gene array analysis of muscle from T2D patients following a 2-week withdrawal of insulin treatment for hyperglycemia identified 85 altered transcripts in comparison with nondiabetic controls; moreover, decreased expression of mRNA central to mitochondrial maintenance (e.g., mitochondrial superoxide dismutase [SOD2]) and mitochondrial OXHPOS was prominent in T2D (82). In the same study, insulin treatment reduced the difference between diabetic and nondiabetic individuals in all but $11 \mathrm{mRNA}$ transcripts, and transcripts pertaining to mitochondrial maintenance and energy production were almost completely normalized, suggesting that loss of insulin action contributes to altered mitochondrial gene expression and function in T2D (82). Insulin resistance and T2D are also associated with reduced mRNA expression of PGC1A and multiple NRF1-dependent genes encoding enzymes that are key to OXPHOS and mitochondrial function (80).

Mitochondrial dynamics during insulin resistance. Mitophagy's influence on mitochondrial quality and insulin sensitivity is an emerging research area. Studies in mice support mitophagy's beneficial effect in maintaining mitochondrial quality and insulin sensitivity $(101,102)$. Similarly, mitophagy mediators such as HSP72 (103, 104) and PTEN-induced putative kinase 1 (PINK1) (105) were reported as decreased in obesity and T2D, while another report showed no change in mitophagic muscle in T2D (106). Interestingly, transgenic mice with muscle deletion of autophagyrelated 7 (Atg7), a manipulation that impairs basal autophagy, have poorly functioning mitochondria but are protected against developing insulin resistance (107). Similarly, muscle-specific deletion of FUN14 domain-containing 1 (Fundc1), which mediates mitophagy, also impairs mitochondrial function but alleviates HFDinduced obesity and insulin resistance (108). Thus, the relationship between mitophagy, mitochondrial function, and insulin resistance requires additional research. Other reviews discuss the relationship between mitophagy and insulin resistance in more detail $(10,56,109)$.

Mitochondrial fission and fusion also play a key role in maintaining the mitochondrial network. Obesity and T2D downregulate mitofusin 2 (MFN2) mRNA, suggesting an imbalance between mitochondrial fusion and fission $(110,111)$. Additionally, muscle MFN2 mRNA positively associates with insulin-mediated glucose oxidation, and increased MFN2 mRNA level may explain increased glucose oxidation following bariatric surgery (111).

Mitochondrial function in the insulin-resistant heart. T2D is also associated with myocardial insulin resistance and increased myocellular lipid accumulation. ${ }^{31} \mathrm{P}-\mathrm{NMR}$ studies show decreased phosphocreatine/ATP ratios in cardiac tissue of obese and T2D subjects (112-114). Data for right atrium heart biopsies in T2D patients demonstrated decreased maximal mitochondrial respiratory capacity for glutamate and FA substrates, and increases in myocardial triglycerides, mitochondrial ROS emission, propensity for mitochondrial permeability transition pore opening, 
and caspase-9 activity, leading to persistent oxidative stress and apoptosis $(115,116)$. Animal studies also support a role for T2D in altering myocardial mitochondrial function, such as decreased maximal mitochondrial ATP production despite increased mitochondrial biogenesis, altered palmitate and glucose oxidation, increased ROS emission, and increased mitochondrial uncoupling $(117,118)$. Decrements in myocardial mitochondrial function appear more severe with advanced T2D progression. Highresolution respirometry of human right atrial tissue in lean, overweight, obese nondiabetic, and T2D individuals found decreases in mitochondrial respiration and mitochondrial coupling efficiency and increased ROS emission in the T2D individuals, while similar observations were absent in nondiabetic individuals (119). Impaired mitochondrial function in the T2D heart associated with increased mitochondrial fragmentation and approximately 5 -fold decreased MFN1 protein levels irrespective of BMI (119). These observations show that T2D associates with decreased myocardial mitochondrial respiration, increased oxidative stress, and mitochondrial fragmentation independent of BMI, while deficits in mitochondrial oxidative capacity and redox balance are less pronounced in obesity.

Mitochondrial function in insulin-resistant AT. Mitochondrial activity in adipocytes crucially regulates the release of free FAs into the circulation, where they can promote insulin resistance and T2D (120). Several studies report reduced mitochondrial content and OXPHOS, PGC1A, and NRF1 mRNA in subcutaneous AT (SAT) in T2D and obesity (121-124). Maximal mitochondrial respiration did not differ in SAT of obese and T2D subjects, suggesting that altered AT mitochondrial function may be secondary to increased BMI rather than T2D (125). The influence of obesity and $\mathrm{T} 2 \mathrm{D}$ on AT mitochondrial function also appears to be depot-specific. In contrast to SAT, obesity increased mitochondrial content in visceral AT, although maximal respiration decreased when normalized to mitochondrial content, indicating impaired mitochondrial function in obesity (126).

Mitochondrial function in the insulin-resistant liver. Insulin resistance appears to have tissue-specific effects on mitochondrial characteristics that likely correlate with the vastly different metabolic demands of divergent insulin-sensitive tissues. For example, initial gene expression studies revealed altered metabolic pathways in T2D patient livers, specifically the upregulation of mRNAs central to OXPHOS, ROS generation, and gluconeogenesis $(127,128)$, which contrasts with the downregulation of mitochondrial mRNAs in muscle. Additionally, increased hepatic OXPHOS mRNA expression was predictive of fasting blood glucose independent of age, BMI, or fasting insulin levels (127). The presence of insulin-dependent and insulin-independent glucose uptake in myocytes and hepatocytes, respectively, may influence how a tissue's energy status regulates its mitochondrial function (129). However, as in muscle, ${ }^{31} \mathrm{P}-\mathrm{NMR}$ measurements of hepatic mitochondrial ATP production reveal 23\%-26\% decreased ATP production in T2D individuals compared with age- and weightmatched nondiabetic controls $(130,131)$. In these studies, hepatic ATP production more strongly associated with hepatic than peripheral insulin sensitivity $(130,131)$. Further, postprandial increases in hepatic ATP concentration were increased 6-fold in obese, insulin-resistant subjects compared with lean controls, suggesting augmented postprandial hepatic metabolism during insulin resistance (132). Likewise, high fructose consumption in obese, T2D individuals depleted hepatic ATP concentrations and impaired recovery from ATP depletion (133). Hepatic ATP content also inversely correlated with BMI (134). These data suggest that despite increasing mitochondrial mRNA expression, T2D impairs hepatic ATP production. The unknown mechanism underlying intriguing differences between hepatic and muscle tissue in response to a meal indicates the need for additional measures of mitochondrial function in $\mathrm{T} 2 \mathrm{D}$ patients.

\section{Potential therapies to rescue mitochondrial defects with insulin resistance}

Exercise. Aerobic exercise is a powerful stimulant of mitochondrial respiration and ATP production $(135,136)$ and improves insulin sensitivity (137). As mentioned above, in obese, insulin-resistant women with PCOS, 12 weeks of aerobic exercise increased mitochondrial respiration and coupling efficiency while decreasing ROS emission and irreversible DNA damage toward those of lean, insulin-sensitive individuals (99). Additionally, improvements in mitochondrial energetics paralleled improvements in insulin sensitivity, which were likely due to improved cellular redox status (99). Mouse experiments also demonstrated that Irs1 and Irs2 were indispensable for increased PGC1A protein content, mitochondrial respiration and ATP production, and mtDNA copy number following exercise training, suggesting that exercise modulates mitochondrial function though insulin signaling (138). Aerobic exercise also prevented age-related declines in mitochondrial oxidative capacity $(93,136,139,140)$ concurrent with improvement in insulin sensitivity. Recent findings indicate that highintensity interval training, rather than moderate aerobic exercise, has the greatest impact toward increasing mitochondrial oxidative capacity and mitochondrial protein synthesis and content while concurrently improving insulin sensitivity in older adults (141). Thus, sedentary lifestyles exacerbate mitochondrial deficits associated with insulin resistance and T2D, which may be at least partially rescued by moderate aerobic or high-intensity exercise.

Mitochondrial uncoupling. OXPHOS, oxidative stress, and heat production are intimately interconnected, and perturbation in one component affects the other two. Mitochondrial uncoupling is the process by which the ETC's proton-motive force uncouples from OXPHOS by proton leak or by uncoupling proteins (UCPs) in the inner mitochondrial membrane, thus generating heat rather than ATP. Under conditions of high dietary fat and glucose, modest mitochondrial uncoupling and heat production can function as a sink for excessive substrates to alleviate oxidative stress, in turn modulating the development of obesity and insulin resistance (142). Muscle-specific Ucp3 overexpression rendered mice resistant to diet-induced obesity despite hyperphagia (143). Similarly, UCP3 mRNA was decreased in muscle from obese women who were resistant to weight loss following caloric restriction (144), and $U C P 3$ positively correlated with resting metabolic rate in Pima Indians, a T2D-susceptible population (145). No clear evidence directly links UCPs with physiological regulation of metabolic rate and energy balance in humans. However, recent reports revealing significant amounts of metabolically active BAT in adults $(146,147)$ indicated a potential role of this mitochondria-rich fat 
in energy regulation. Preclinical studies indicate BAT's potential role in glucose homeostasis (148). Furthermore, exercise-induced "browning" of WAT via many molecular factors has been proposed as a potential approach to influencing energy balance (149).

Oral ingestion of niclosamide ethanolamine salt, which induces mild mitochondrial uncoupling, by diabetic $d b / d b$ mice increased energy expenditure, prevented HFD-induced insulin resistance, and improved glycemic control (150). Thus, mild mitochondrial uncoupling may offer therapeutic value for the treatment of T2D. However, it should be noted that uncontrolled mitochondrial uncoupling could lead to a life-threatening increase in body temperature and ATP depletion (151).

\section{Concluding remarks}

Recently our understanding of the dynamic relationship between mitochondrial function and diabetes has advanced tremendously. This interactive relationship is not surprising given that altered fuel metabolism characterizes both insulin-deficient and insulinresistant diabetes. Research has identified insulin as a critical regulator of mitochondrial biogenesis and function in numerous tissues. Both insulin deficiency and resistance result in oxidative stress and consequent oxidative damage to DNA and proteins that likely contribute to diabetic complications. Insulin not only regulates oxidative metabolism and ROS emission, but ROS can affect insulin actions, as occurs following HFD. Although development of insulin resistance does not require impaired mitochondrial function, pathways promoting insulin resistance may impair mitochondrial function and further increase ROS production, resulting in a detrimental feedback loop. Aerobic exercise and caloric restriction disrupt this vicious loop potentially by preventing accumulation of damaged mitochondrial proteome with substantial improvement of insulin sensitivity. Although therapies targeted to enhance $\beta$-oxidation, as occurs following exercise, may improve insulin sensitivity by reducing adiposity, it remains to be determined whether increased fuel oxidation may increase oxidative stress.
Mitochondria are highly adaptable and dynamic within different environments, including various cell types and tissues. Consideration of this adaptability is critically important in planning and interpreting studies using variable experimental conditions (e.g., in vivo versus in vitro, different tissue/cell types, temperature differences, etc.). These aspects are reviewed elsewhere (e.g., refs. 152, 153).

Although mitochondrial respiration in resting muscle is unlikely to have any major impact on energy balance or fuel metabolism, maximal mitochondrial capacity to produce ATP is a key determinant of maximal aerobic capacity (154), which in turn determines exercise capacity with substantial impact on reducing mortality in various chronic diseases, including T2D (155). However, in many other organs, including brain and liver, methodologies to measure resting-state mitochondrial respiration are critically important to understanding the role of mitochondria in normal physiology and pathological states in diabetes. Given the epidemic levels of T2D and high incidence of comorbid dementia, understanding links between diabetes and mitochondrial impairment in cognitive decline is of great interest. However, unlike muscle, different anatomical regions of brain have distinct functions and variable distribution of mitochondria and IRs, necessitating studies with brain region-specific focus. Greater understanding of the molecular regulatory points altered by insulin resistance and deficiency offers opportunities to target therapeutic molecules to mitochondria with the potential to prevent $\mathrm{T} 2 \mathrm{D}$ and diabetic complications.

\section{Acknowledgments}

This work was supported by grants from the NIH (R01DK101402, U24DK100469, and U24KD112326 to KSN and T32AG49672 to GNR) and by the Murdock-Dole Professorship (to KSN).

Address correspondence to: K. Sreekumaran Nair, Mayo Clinic, 200 First Street SW, Joseph 5-194, Rochester, Minnesota 55905, USA. Phone: 507.255.2415; Email: nair.k@mayo.edu.
1. Bommer C, et al. Global economic burden of diabetes in adults: projections from 2015 to 2030.

Diabetes Care. 2018;41(5):963-970.

2. American Diabetes Association. Position statement: 2. Classification and diagnosis of diabetes. Diabetes Care. 2015;38(suppl 1):S8-S16.

3. Bogardus C, Taskinen MR, Zawadzki J, Lillioja S, Mott D, Howard BV. Increased resting metabolic rates in obese subjects with non-insulindependent diabetes mellitus and the effect of sulfonylurea therapy. Diabetes. 1986;35(1):1-5.

4. Nair KS, Halliday D, Garrow JS. Increased energy expenditure in poorly controlled Type 1 (insulindependent) diabetic patients. Diabetologia. 1984;27(1):13-16.

5. Nair KS, Webster J, Garrow JS. Effect of impaired glucose tolerance and type II diabetes on resting metabolic rate and thermic response to a glucose meal in obese women. Metab Clin Exp. 1986;35(7):640-644.

6. Ravussin E, et al. Thermic effect of infused glucose and insulin in man. Decreased response with increased insulin resistance in obesity and noninsulin-dependent diabetes mellitus. JClin
Invest. 1983;72(3):893-902.

7. Dröge W. Free radicals in the physiological control of cell function. Physiol Rev. 2002;82(1):47-95.

8. Liesa M, Palacín M, Zorzano A. Mitochondrial dynamics in mammalian health and disease. Physiol Rev. 2009;89(3):799-845.

9. Anderson S, et al. Sequence and organization of the human mitochondrial genome. Nature. 1981;290(5806):457-465.

10. Liesa M, Shirihai OS. Mitochondrial dynamics in the regulation of nutrient utilization and energy expenditure. Cell Metab. 2013;17(4):491-506.

11. Cheng Z, Tseng Y, White MF. Insulin signaling meets mitochondria in metabolism. Trends Endocrinol Metab. 2010;21(10):589-598.

12. Hesselink MK, Schrauwen-Hinderling V, Schrauwen P. Skeletal muscle mitochondria as a target to prevent or treat type 2 diabetes mellitus. Nat Rev Endocrinol. 2016;12(11):633-645.

13. Koliaki C, Roden M. Alterations of mitochondrial function and insulin sensitivity in human obesity and diabetes mellitus. Annu Rev Nutr. 2016;36:337-367.

14. Nunnari J, Suomalainen A. Mitochondria: in sick- ness and in health. Cell. 2012;148(6):1145-1159.

15. Wai T, Langer T. Mitochondrial dynamics and metabolic regulation. Trends Endocrinol Metab. 2016;27(2):105-117.

16. De Meyts $P$. The insulin receptor and its signal transduction network. In: De Groot LJ, et al., eds. Endotext. South Dartmouth, Massachusetts, USA: MDText.com, Inc.; 2000.

17. Cunningham JT, Rodgers JT, Arlow DH, Vazquez F, Mootha VK, Puigserver P. mTOR controls mitochondrial oxidative function through a YY1-PGC-1alpha transcriptional complex. Nature. 2007;450(7170):736-740.

18. Schieke SM, et al. The mammalian target of rapamycin (mTOR) pathway regulates mitochondrial oxygen consumption and oxidative capacity. J Biol Chem. 2006;281(37):27643-27652.

19. Cheng Z, et al. Foxo1 integrates insulin signaling with mitochondrial function in the liver. Nat Med. 2009;15(11):1307-1311.

20. Daitoku H, Yamagata K, Matsuzaki H, Hatta M, Fukamizu A. Regulation of PGC-1 promoter activity by protein kinase $B$ and the forkhead transcription factor FKHR. Diabetes. 
2003;52(3):642-649.

21. Scarpulla RC. Metabolic control of mitochondrial biogenesis through the PGC-1 family regulatory network. Biochim Biophys Acta. 2011;1813(7):1269-1278.

22. Wiedemann N, Frazier AE, Pfanner N. The protein import machinery of mitochondria. J Biol Chem. 2004;279(15):14473-14476.

23. Barrett EJ, Schwartz RG, Francis CK, Zaret BL. Regulation by insulin of myocardial glucose and fatty acid metabolism in the conscious dog. JClin Invest. 1984;74(3):1073-1079.

24. Nair KS, Ford GC, Ekberg K, Fernqvist-Forbes E, Wahren J. Protein dynamics in whole body and in splanchnic and leg tissues in type I diabetic patients. JClin Invest. 1995;95(6):2926-2937.

25. James HA, O'Neill BT, Nair KS. Insulin regulation of proteostasis and clinical implications. Cell Metab. 2017;26(2):310-323.

26. Jaleel A, et al. Differential effects of insulin deprivation and systemic insulin treatment on plasma protein synthesis in type 1 diabetic people. Am JPhysiol Endocrinol Metab. 2009;297(4):E889-E897.

27. Stump CS, Short KR, Bigelow ML, Schimke JM, Nair KS. Effect of insulin on human skeletal muscle mitochondrial ATP production, protein synthesis, and mRNA transcripts. Proc Natl Acad Sci U S A. 2003;100(13):7996-8001.

28. Robinson MM, et al. High insulin combined with essential amino acids stimulates skeletal muscle mitochondrial protein synthesis while decreasing insulin sensitivity in healthy humans. JClin Endocrinol Metab. 2014;99(12):E2574-E2583.

29. Chow LS, Albright RC, Bigelow ML, Toffolo G, Cobelli C, Nair KS. Mechanism of insulin's anabolic effect on muscle: measurements of muscle protein synthesis and breakdown using aminoacyl-tRNA and other surrogate measures. Am JPhysiol Endocrinol Metab. 2006;291(4):E729-E736.

30. Gelfand RA, Barrett EJ. Effect of physiologic hyperinsulinemia on skeletal muscle protein synthesis and breakdown in man. J Clin Invest. 1987;80(1):1-6.

31. Barazzoni R, Short KR, Asmann Y, Coenen-Schimke JM, Robinson MM, Nair KS. Insulin fails to enhance mTOR phosphorylation, mitochondrial protein synthesis, and ATP production in human skeletal muscle without amino acid replacement. Am J Physiol Endocrinol Metab. 2012;303(9):E1117-E1125.

32. Ling $\mathrm{C}$, et al. Multiple environmental and genetic factors influence skeletal muscle PGC- $1 \alpha$ and PGC-1 $\beta$ gene expression in twins. J Clin Invest. 2004;114(10):1518-1526.

33. Asmann YW, et al. Skeletal muscle mitochondrial functions, mitochondrial DNA copy numbers, and gene transcript profiles in type 2 diabetic and nondiabetic subjects at equal levels of low or high insulin and euglycemia. Diabetes. 2006;55(12):3309-3319.

34. Nair KS, Halliday D, Garrow JS. Thermic response to isoenergetic protein, carbohydrate or fat meals in lean and obese subjects. Clin Sci. 1983;65(3):307-312.

35. Boudina S, et al. Contribution of impaired myocardial insulin signaling to mitochondrial dysfunction and oxidative stress in the heart. Circulation. 2009;119(9):1272-1283.
36. Franko A, et al. Complete failure of insulintransmitted signaling, but not obesity-induced insulin resistance, impairs respiratory chain function in muscle. J Mol Med. 2012;90(10):1145-1160.

37. Kleinridders A, et al. Insulin resistance in brain alters dopamine turnover and causes behavioral disorders. Proc Natl Acad Sci US A. 2015;112(11):3463-3468.

38. Boucher J, et al. Differential roles of insulin and IGF-1 receptors in adipose tissue development and function. Diabetes. 2016;65(8):2201-2213.

39. Liu $S$, et al. Insulin signaling regulates mitochondrial function in pancreatic beta-cells. PLoS One. 2009;4(11):e7983.

40. Riehle C, et al. Insulin receptor substrate signaling suppresses neonatal autophagy in the heart. J Clin Invest. 2013;123(12):5319-5333.

41. Laustsen PG, et al. Essential role of insulin and insulin-like growth factor 1 receptor signaling in cardiac development and function. Mol Cell Biol. 2007;27(5):1649-1664.

42. Dong XC, et al. Inactivation of hepatic Foxo1 by insulin signaling is required for adaptive nutrient homeostasis and endocrine growth regulation. Cell Metab. 2008;8(1):65-76.

43. Zhao N, et al. Apolipoprotein E4 impairs neuronal insulin signaling by trapping insulin receptor in the endosomes. Neuron. 2017;96(1):115-129.e5.

44. Janson J, Laedtke T, Parisi JE, O'Brien P, Petersen $\mathrm{RC}$, Butler PC. Increased risk of type 2 diabetes in Alzheimer disease. Diabetes. 2004;53(2):474-481.

45. Talbot K, et al. Demonstrated brain insulin resistance in Alzheimer's disease patients is associated with IGF-1 resistance, IRS-1 dysregulation, and cognitive decline. J Clin Invest. 2012;122(4):1316-1338.

46. Lin MT, Beal MF. Mitochondrial dysfunction and oxidative stress in neurodegenerative diseases. Nature. 2006;443(7113):787-795.

47. Benedict FG, Joslin EP. Metabolism in Diabetes Mellitus. Washington, DC, USA: Carnegie Institution of Washington; 1910.

48. Allen FM, Du Bois EF. Clinical calorimetry. Seventeenth paper: metabolism and treatment in diabetes. Arch Intern Med (Chic). 1916;17(6_2):1010-1059.

49. Charlton MR, Nair KS. Role of hyperglucagonemia in catabolism associated with type 1 diabetes: effects on leucine metabolism and the resting metabolic rate. Diabetes. 1998;47(11):1748-1756.

50. Nair KS. Hyperglucagonemia increases resting metabolic rate in man during insulin deficiency. J Clin Endocrinol Metab. 1987;64(5):896-901.

51. Wang Z, Pi-Sunyer FX, Kotler DP, Wang J, Pierson RN, Heymsfield SB. Magnitude and variation of ratio of total body potassium to fat-free mass: a cellular level modeling study. Am J Physiol Endocrinol Metab. 2001;281(1):E1-E7.

52. Karakelides $\mathrm{H}$, et al. Effect of insulin deprivation on muscle mitochondrial ATP production and gene transcript levels in type 1 diabetic subjects. Diabetes. 2007;56(11):2683-2689.

53. Item F, et al. Mitochondrial capacity is affected by glycemic status in young untrained women with type 1 diabetes but is not impaired relative to healthy untrained women. Am J Physiol Regul Integr Comp Physiol. 2011;301(1):R60-R66.
54. Zabielski P, et al. Altered skeletal muscle mitochondrial proteome as the basis of disruption of mitochondrial function in diabetic mice. Diabetes. 2016;65(3):561-573.

55. Robinson MM, Dasari S, Karakelides H, Bergen HR, Nair KS. Release of skeletal muscle peptide fragments identifies individual proteins degraded during insulin deprivation in type 1 diabetic humans and mice. Am J Physiol Endocrinol Metab. 2016;311(3):E628-E637.

56. Jung HS, Lee MS. Role of autophagy in diabetes and mitochondria. Ann N Y Acad Sci. 2010;1201:79-83.

57. Zabielski $\mathrm{P}$, et al. Impact of insulin deprivation and treatment on sphingolipid distribution in different muscle subcellular compartments of streptozotocin-diabetic C57Bl/6 mice. Am JPhysiol Endocrinol Metab. 2014;306(5):E529-E542.

58. Bugger $\mathrm{H}$, et al. Type 1 diabetic akita mouse hearts are insulin sensitive but manifest structurally abnormal mitochondria that remain coupled despite increased uncoupling protein 3. Diabetes. 2008;57(11):2924-2932.

59. Bugger $\mathrm{H}$, et al. Tissue-specific remodeling of the mitochondrial proteome in type 1 diabetic akita mice. Diabetes. 2009;58(9):1986-1997.

60. Shen X, et al. Cardiac mitochondrial damage and biogenesis in a chronic model of type 1 diabetes. Am J Physiol Endocrinol Metab. 2004;287(5):E896-E905.

61. Glyn-Jones S, Song S, Black MA, Phillips AR, Choong SY, Cooper GJ. Transcriptomic analysis of the cardiac left ventricle in a rodent model of diabetic cardiomyopathy: molecular snapshot of a severe myocardial disease. Physiol Genomics. 2007;28(3):284-293.

62. Afkarian M, et al. Clinical manifestations of kidney disease among US adults with diabetes, 1988-2014. JAMA. 2016;316(6):602-610.

63. de Cavanagh EM, et al. Renal mitochondrial impairment is attenuated by AT1 blockade in experimental Type I diabetes. Am J Physiol Heart Circ Physiol. 2008;294(1):H456-H465.

64. Katyare SS, Satav JG. Effect of streptozotocininduced diabetes on oxidative energy metabolism in rat kidney mitochondria. A comparative study of early and late effects. Diabetes Obes Metab. 2005;7(5):555-562.

65. Raza H, Prabu SK, John A, Avadhani NG. Impaired mitochondrial respiratory functions and oxidative stress in streptozotocin-induced diabetic rats. Int J Mol Sci. 2011;12(5):3133-3147.

66. Rosca MG, et al. Glycation of mitochondrial proteins from diabetic rat kidney is associated with excess superoxide formation. Am J Physiol Renal Physiol. 2005;289(2):F420-F430.

67. Swan EJ, Maxwell AP, McKnight AJ. Distinct methylation patterns in genes that affect mitochondrial function are associated with kidney disease in blood-derived DNA from individuals with Type 1 diabetes. Diabet Med. 2015;32(8):1110-1115.

68. Moreira PI, Santos MS, Moreno AM, Proença T, Seiça R, Oliveira CR. Effect of streptozotocininduced diabetes on rat brain mitochondria. J Neuroendocrinol. 2004;16(1):32-38.

69. Santos RX, et al. Insulin therapy modulates mitochondrial dynamics and biogenesis, autophagy 
and tau protein phosphorylation in the brain of type 1 diabetic rats. Biochim Biophys Acta. 2014;1842(7):1154-1166.

70. Kleinridders A, Ferris HA, Cai W, Kahn CR. Insulin action in brain regulates systemic metabolism and brain function. Diabetes. 2014;63(7):2232-2243.

71. Shao L, et al. Mitochondrial involvement in psychiatric disorders. Ann Med. 2008;40(4):281-295.

72. Wang X, Wang W, Li L, Perry G, Lee HG, Zhu X. Oxidative stress and mitochondrial dysfunction in Alzheimer's disease. Biochim Biophys Acta. 2014;1842(8):1240-1247.

73. Blake R, Trounce IA. Mitochondrial dysfunction and complications associated with diabetes. Biochim Biophys Acta. 2014;1840(4):1404-1412.

74. Fosslien E. Mitochondrial medicine - molecular pathology of defective oxidative phosphorylation. Ann Clin Lab Sci. 2001;31(1):25-67.

75. Kelley DE, He J, Menshikova EV, Ritov VB. Dysfunction of mitochondria in human skeletal muscle in type 2 diabetes. Diabetes. 2002;51(10):2944-2950.

76. Lowell BB, Shulman GI. Mitochondrial dysfunction and type 2 diabetes. Science. 2005;307(5708):384-387.

77. Simoneau JA, Veerkamp JH, Turcotte LP, Kelley DE. Markers of capacity to utilize fatty acids in human skeletal muscle: relation to insulin resistance and obesity and effects of weight loss. FASEB J. 1999;13(14):2051-2060.

78. Mootha VK, et al. PGC-1 $\alpha$-responsive genes involved in oxidative phosphorylation are coordinately downregulated in human diabetes. Nat Genet. 2003;34(3):267-273.

79. Morino K, et al. Reduced mitochondrial density and increased IRS-1 serine phosphorylation in muscle of insulin-resistant offspring of type 2 diabetic parents.JClin Invest. 2005;115(12):3587-3593.

80. Patti ME, et al. Coordinated reduction of genes of oxidative metabolism in humans with insulin resistance and diabetes: potential role of PGC1 and NRF1. Proc Natl Acad Sci US A. 2003;100(14):8466-8471.

81. Petersen KF, Dufour S, Befroy D, Garcia R, Shulman GI. Impaired mitochondrial activity in the insulinresistant offspring of patients with type 2 diabetes. NEngl JMed.2004;350(7):664-671.

82. Sreekumar R, Halvatsiotis P, Schimke JC, Nair KS. Gene expression profile in skeletal muscle of type 2 diabetes and the effect of insulin treatment. Diabetes. 2002;51(6):1913-1920.

83. Befroy DE, et al. Impaired mitochondrial substrate oxidation in muscle of insulin-resistant offspring of type 2 diabetic patients. Diabetes. 2007;56(5):1376-1381.

84. Andersen P, Saltin B. Maximal perfusion of skeletal muscle in man. JPhysiol (Lond). 1985;366:233-249.

85. Holloszy JO. Skeletal muscle "mitochondrial deficiency" does not mediate insulin resistance. Am JClin Nutr. 2009;89(1):463S-466S.

86. Han DH, Hancock CR, Jung SR, Higashida K, Kim SH, Holloszy JO. Deficiency of the mitochondrial electron transport chain in muscle does not cause insulin resistance. PLoS One. 2011;6(5):e19739.

87. Hancock CR, et al. High-fat diets cause insulin resistance despite an increase in mus- cle mitochondria. Proc Natl Acad Sci U S A. 2008;105(22):7815-7820.

88. Lanza IR, et al. Influence of fish oil on skeletal muscle mitochondrial energetics and lipid metabolites during high-fat diet. Am J Physiol Endocrinol Metab. 2013;304(12):E1391-E1403.

89. Turner N, et al. Excess lipid availability increases mitochondrial fatty acid oxidative capacity in muscle: evidence against a role for reduced fatty acid oxidation in lipid-induced insulin resistance in rodents. Diabetes. 2007;56(8):2085-2092.

90. Nair KS, et al. Asian Indians have enhanced skeletal muscle mitochondrial capacity to produce ATP in association with severe insulin resistance. Diabetes. 2008;57(5):1166-1175.

91. Johnson ML, et al. Mechanism by which caloric restriction improves insulin sensitivity in sedentary obese adults. Diabetes. 2016;65(1):74-84.

92. Menshikova EV, et al. Calorie restriction-induced weight loss and exercise have differential effects on skeletal muscle mitochondria despite similar effects on insulin sensitivity. J Gerontol A Biol Sci Med Sci. 2017;73(1):81-87.

93. Irving BA, Short KR, Nair KS, Stump CS. Nine days of intensive exercise training improves mitochondrial function but not insulin action in adult offspring of mothers with type 2 diabetes. JClin Endocrinol Metab. 2011;96(7):E1137-E1141.

94. Han DH, Nolte LA, Ju JS, Coleman T, Holloszy JO, Semenkovich CF. UCP-mediated energy depletion in skeletal muscle increases glucose transport despite lipid accumulation and mitochondrial dysfunction. Am JPhysiol Endocrinol Metab. 2004;286(3):E347-E353.

95. Wredenberg A, et al. Respiratory chain dysfunction in skeletal muscle does not cause insulin resistance. Biochem Biophys Res Commun. 2006;350(1):202-207.

96. Anderson EJ, et al. Mitochondrial $\mathrm{H} 2 \mathrm{O} 2$ emission and cellular redox state link excess fat intake to insulin resistance in both rodents and humans. J Clin Invest. 2009;119(3):573-581.

97. Fisher-Wellman KH, et al. Mitochondrial respiratory capacity and content are normal in young insulin-resistant obese humans. Diabetes. 2014;63(1):132-141.

98. Evans JL, Goldfine ID, Maddux BA, Grodsky GM. Oxidative stress and stress-activated signaling pathways: a unifying hypothesis of type 2 diabetes. Endocr Rev. 2002;23(5):599-622.

99. Konopka AR, et al. Defects in mitochondrial efficiency and $\mathrm{H} 2 \mathrm{O} 2$ emissions in obese women are restored to a lean phenotype with aerobic exercise training. Diabetes. 2015;64(6):2104-2115.

100.Christin L, Nacht CA, Vernet O, Ravussin $\mathrm{E}$, Jéquier $\mathrm{E}$, Acheson KJ. Insulin. Its role in the thermic effect of glucose. JClin Invest. 1986;77(6):1747-1755.

101.Drew BG, et al. HSP72 is a mitochondrial stress sensor critical for Parkin action, oxidative metabolism, and insulin sensitivity in skeletal muscle. Diabetes. 2014;63(5):1488-1505.

102. Henstridge DC, et al. Activating HSP72 in rodent skeletal muscle increases mitochondrial number and oxidative capacity and decreases insulin resistance. Diabetes. 2014;63(6):1881-1894.

103. Bruce CR, Carey AL, Hawley JA, Febbraio MA. Intramuscular heat shock protein 72 and heme oxygenase- $1 \mathrm{mRNA}$ are reduced in patients with type 2 diabetes: evidence that insulin resistance is associated with a disturbed antioxidant defense mechanism. Diabetes. 2003;52(9):2338-2345.

104. Chung J, et al. HSP72 protects against obesityinduced insulin resistance. Proc Natl Acad Sci U S A 2008;105(5):1739-1744.

105. Scheele C, et al. Altered regulation of the PINK1 locus: a link between type 2 diabetes and neurodegeneration? FASEB J. 2007;21(13):3653-3665.

106. Kruse R, Vind BF, Petersson SJ, Kristensen JM, Højlund K. Markers of autophagy are adapted to hyperglycaemia in skeletal muscle in type 2 diabetes. Diabetologia. 2015;58(9):2087-2095

107. Kim KH, et al. Autophagy deficiency leads to protection from obesity and insulin resistance by inducing Fgf21 as a mitokine. Nat Med . 2013;19(1):83-92.

108. Fu T, et al. Mitophagy directs muscle-adipose crosstalk to alleviate dietary obesity. Cell Rep. 2018;23(5):1357-1372.

109. Kim I, Rodriguez-Enriquez S, Lemasters JJ. Selective degradation of mitochondria by mitophagy. Arch Biochem Biophys. 2007;462(2):245-253.

110. Bach D, et al. Expression of Mfn2, the CharcotMarie-Tooth neuropathy type 2A gene, in human skeletal muscle: effects of type 2 diabetes, obesity, weight loss, and the regulatory role of tumor necrosis factor alpha and interleukin-6. Diabetes. 2005;54(9):2685-2693.

111. Mingrone G, Manco M, Calvani M, Castagneto M, Naon D, Zorzano A. Could the low level of expression of the gene encoding skeletal muscle mitofusin-2 account for the metabolic inflexibility of obesity? Diabetologia. 2005;48(10):2108-2114.

112. Diamant M, et al. Diastolic dysfunction is associated with altered myocardial metabolism in asymptomatic normotensive patients with well-controlled type 2 diabetes mellitus. J Am Coll Cardiol. 2003;42(2):328-335.

113. Perseghin $\mathrm{G}$, et al. Abnormal left ventricular energy metabolism in obese men with preserved systolic and diastolic functions is associated with insulin resistance. Diabetes Care. 2007;30(6):1520-1526.

114. Scheuermann-Freestone M, et al. Abnormal cardiac and skeletal muscle energy metabolism in patients with type 2 diabetes. Circulation. 2003;107(24):3040-3046.

115. Anderson EJ, Kypson AP, Rodriguez E, Anderson CA, Lehr EJ, Neufer PD. Substrate-specific derangements in mitochondrial metabolism and redox balance in the atrium of the type 2 diabetic human heart.JAm Coll Cardiol. 2009;54(20):1891-1898.

116. Anderson EJ, Rodriguez E, Anderson CA, Thayne K, Chitwood WR, Kypson AP. Increased propensity for cell death in diabetic human heart is mediated by mitochondrial-dependent pathways. Am J Physiol Heart Circ Physiol. 2011;300(1):H118-H124.

117. Boudina S, et al. Mitochondrial energetics in the heart in obesity-related diabetes: direct evidence for increased uncoupled respiration and activation of uncoupling proteins. Diabetes. 2007;56(10):2457-2466.

118. Buchanan J, et al. Reduced cardiac efficiency and altered substrate metabolism precedes the onset of hyperglycemia and contractile dysfunction in two 
mouse models of insulin resistance and obesity. Endocrinology. 2005;146(12):5341-5349.

119. Montaigne D, et al. Myocardial contractile dysfunction is associated with impaired mitochondrial function and dynamics in type 2 diabetic but not in obese patients. Circulation. 2014;130(7):554-564.

120. Frayn KN, Langin D, Karpe F. Fatty acid-induced mitochondrial uncoupling in adipocytes is not a promising target for treatment of insulin resistance unless adipocyte oxidative capacity is increased. Diabetologia. 2008;51(3):394-397.

121. Bogacka I, Xie H, Bray GA, Smith SR. Pioglitazone induces mitochondrial biogenesis in human subcutaneous adipose tissue in vivo. Diabetes. 2005;54(5):1392-1399.

122.Jahansouz C, et al. Roux-en-Y gastric bypass acutely decreases protein carbonylation and increases expression of mitochondrial biogenesis genes in subcutaneous adipose tissue. Obes Surg. 2015;25(12):2376-2385.

123. Mustelin L, et al. Acquired obesity and poor physical fitness impair expression of genes of mitochondrial oxidative phosphorylation in monozygotic twins discordant for obesity. Am JPhysiol Endocrinol Metab. 2008;295(1):E148-E154.

124. Semple RK, et al. Expression of the thermogenic nuclear hormone receptor coactivator PGC-1 $\alpha$ is reduced in the adipose tissue of morbidly obese subjects. Int JObes Relat Metab Disord. 2004;28(1):176-179.

125. Hansen $\mathrm{M}$, et al. Adipose tissue mitochondrial respiration and lipolysis before and after a weight loss by diet and RYGB. Obesity (Silver Spring). 2015;23(10):2022-2029.

126.Kraunsøe R, et al. Mitochondrial respiration in subcutaneous and visceral adipose tissue from patients with morbid obesity. JPhysiol (Lond). 2010;588(pt 12):2023-2032.

127. Misu H, et al. Genes involved in oxidative phosphorylation are coordinately upregulated with fasting hyperglycaemia in livers of patients with type 2 diabetes. Diabetologia. 2007;50(2):268-277.

128. Takamura $\mathrm{T}$, et al. Obesity upregulates genes involved in oxidative phosphorylation in livers of diabetic patients. Obesity (Silver Spring). 2008;16(12):2601-2609.

129. Mitchell T, Chacko B, Ballinger SW, Bailey SM, Zhang J, Darley-Usmar V. Convergent mechanisms for dysregulation of mitochondrial quality control in metabolic disease: implications for mitochondrial therapeutics. Biochem Soc Trans. 2013;41(1):127-133.

130.Schmid AI, Szendroedi J, Chmelik M, Krssák M, Moser E, Roden M. Liver ATP synthesis is lower and relates to insulin sensitivity in patients with type 2 diabetes. Diabetes Care. 2011;34(2):448-453.

131. Szendroedi J, et al. Abnormal hepatic energy homeostasis in type 2 diabetes. Hepatology. 2009;50(4):1079-1086.

132. Fritsch M, et al. Time course of postprandial hepatic phosphorus metabolites in lean, obese, and type 2 diabetes patients. Am J Clin Nutr. 2015;102(5):1051-1058.

133. Abdelmalek MF, et al. Higher dietary fructose is associated with impaired hepatic adenosine triphosphate homeostasis in obese individuals with type 2 diabetes. Hepatology. 2012;56(3):952-960.

134. Nair S, Chacko VP, Arnold C, Diehl AM.

Hepatic ATP reserve and efficiency of replenishing: comparison between obese and nonobese normal individuals. Am J Gastroenterol. 2003;98(2):466-470.

135. Holloszy JO. Biochemical adaptations in muscle. Effects of exercise on mitochondrial oxygen uptake and respiratory enzyme activity in skeletal muscle. J Biol Chem. 1967;242(9):2278-2282.

136. Lanza IR, et al. Endurance exercise as a countermeasure for aging. Diabetes. 2008;57(11):2933-2942.

137. Goodyear LJ, Kahn BB. Exercise, glucose transport, and insulin sensitivity. Anпи Rev Med. 1998;49:235-261.

138. Riehle C, et al. Insulin receptor substrates are essential for the bioenergetic and hypertrophic response of the heart to exercise training. Mol Cell Biol. 2014;34(18):3450-3460.

139. Irving BA, Lanza IR, Henderson GC, Rao RR, Spiegelman BM, Nair KS. Combined training enhances skeletal muscle mitochondrial oxidative capacity independent of age. JClin Endocrinol Metab. 2015;100(4):1654-1663.

140.Short KR, et al. Impact of aerobic exercise training on age-related changes in insulin sensitivity and muscle oxidative capacity. Diabetes. 2003;52(8):1888-1896.

141. Robinson MM, et al. Enhanced protein translation underlies improved metabolic and physical adaptations to different exercise training modes in young and old humans. Cell Metab. 2017;25(3):581-592.
142.Schrauwen P, Hesselink MK. Oxidative capacity, lipotoxicity, and mitochondrial damage in type 2 diabetes. Diabetes. 2004;53(6):1412-1417.

143. Clapham JC, et al. Mice overexpressing human uncoupling protein-3 in skeletal muscle are hyperphagic and lean. Nature. 2000;406(6794):415-418.

144. Harper ME, et al. Decreased mitochondrial proton leak and reduced expression of uncoupling protein 3 in skeletal muscle of obese diet-resistant women. Diabetes. 2002;51(8):2459-2466.

145. Schrauwen P, Xia J, Bogardus C, Pratley RE, Ravussin E. Skeletal muscle uncoupling protein 3 expression is a determinant of energy expenditure in Pima Indians. Diabetes. 1999;48(1):146-149.

146.Virtanen KA, et al. Functional brown adipose tissue in healthy adults. $N$ Engl J Med. 2009;360(15):1518-1525.

147. Cypess AM, et al. Identification and importance of brown adipose tissue in adult humans. $N$ Engl $J$ Med. 2009;360(15):1509-1517.

148.Stanford KI, et al. Brown adipose tissue regulates glucose homeostasis and insulin sensitivity. J Clin Invest. 2013;123(1):215-223.

149. Spiegelman BM. Banting Lecture 2012. Regulation of adipogenesis: toward new therapeutics for metabolic disease. Diabetes. 2013;62(6):1774-1782.

150. Tao H, Zhang Y, Zeng X, Shulman GI, Jin S. Niclosamide ethanolamine-induced mild mitochondrial uncoupling improves diabetic symptoms in mice. Nat Med. 2014;20(11):1263-1269.

151. Diehl AM, Hoek JB. Mitochondrial uncoupling: role of uncoupling protein anion carriers and relationship to thermogenesis and weight control "the benefits of losing control". J Bioenerg Biomembr. 1999;31(5):493-506.

152. Milane L, Trivedi M, Singh A, Talekar M, Amiji M. Mitochondrial biology, targets, and drug delivery. J Control Release. 2015;207:40-58.

153. Kuznetsov AV, Hermann M, Saks V, Hengster P, Margreiter R. The cell-type specificity of mitochondrial dynamics. Int J Biochem Cell Biol. 2009;41(10):1928-1939.

154. Short KR, et al. Decline in skeletal muscle mitochondrial function with aging in humans. Proc Natl Acad Sci U S A. 2005;102(15):5618-5623.

155. Myers J, Prakash M, Froelicher V, Do D, Partington S, Atwood JE. Exercise capacity and mortality among men referred for exercise testing. $N$ Engl J Med. 2002;346(11):793-801. 